the great Papuan subregion, that has hitherto appeared. At the same time the authors have not attempted to make a perfect faunistic work of it. Only such species as are represented in the collections made by the Italian travellers, Beccari and D'Albertis, on their various joint and several expeditions, and in the collections sent to Genoa, by Herr Bruijn of Ternate are enumerated in the list. On the other hand the mass of these collections is so greatconsisting of 3,000 examples from 44 different localities, and the series thus brought together is so much more nearly perfect than that which any other authors have had before them-that the result has been to give us an excellent idea of the general character of the reptiles and batrachians of this division of the earth's surface. Let us, therefore, look through the pages of Messrs. Peters and Doria's excellent memoir, and see what general views we can obtain from it as to the peculiarities of this littleknown branch of the Papuan fauna.

In the first place, land-tortoises are few in the Papuan sub-region. Our list contains but two species, one from Amboina and Celebes, the other from the southern extremity of New Guinea, and very doubtfully distinguishable from an Australian species.

Crocodilians are also scarce. The series contained examples but of one species-Crocodilus porosus-which extends from India into Northern Australia.

Of lizards, besides the monitors, of which genus not less than 16 species are contained in the list, the great mass are Skinks, Geekos and Agamids. As in Australia the Skinks are especially numerous, upwards of 30 species being represented in the series, of which 8 are now described for the first time.

The ophidians are also well represented in the Papuan fauna, the series examined by our authors affording examples of 54 species. Amongst the Boas Liasis and Chondropython are characteristic Papuan forms, whilst the Australian Morelia also extends into New Guinea. But no greater sign of the essential unity of the Australian and Papuan faunas can be shown than the presence in New Guinea of the three Elapine genera, Diementia, Pseudechis and Acanthophis, all characteristic forms of the Australian continent. At the same time the presence of an Ophiophagus in New Guinea, proves that an intruding element from the north has reached thus far.

About 20 batrachians close the list, amongst which Limnodytes and Hyla seem to be the most prevalent genera. The Australian Pelodryas carulea is abundant all through the sub-region. A new and very singular form obtained by Beccari in the interior of New Guinea, near the river Wa-Sampson is characterized as Sphenophryne comuta, and a second, obtained, by the same explorer on Mount Corfak as Xenobatrachus ophiodon. The latter shows some points of affinity to the Australian Myobatrachus.

Seven excellent lithographic plates illustrate some of the rarities described in this memoir, and two maps are added to show the exact localities where the collections were found. The maps we see with great pleasure, as in our opinion no zoological work of a faunistic character can in these days be considered complete without such an appendage.

\section{THE METEOROLOGICAL SOCIETY LECTURES}

$\triangle$ COURSE of six lectures on meteorology was recently $A$ delivered under the auspices of the Meteorological Society at the Institution of Civil Engineers. The purpose of these lectures, we believe, is to spread a knowledge of the known facts and principles of meteorology, and in this useful mission we cannot but wish the Society every success. We here give abstracts of two of these lectures, by Mr. J. K. Laughton and the Rev. W. Clement Ley. The subject of Mr. Laughton's lecture was-
Air Temperature, its Distribution and Range

After calling attention to the importance of climatic knowledge the lecturer dweit on the fact that though all beat as affect. ing climate emanates directly or indirectly from the sun, temperatures have but little relation to latitude except when the distances are very great. He illustrated this by reference to isothermal and isabnormal maps, and went on to speak in some detail of the several causes of the disagreement between isotherms and parallels of latitude. Locally there is a very great difference between the temperatures of adjacent localities on account of the sunny aspect or sheltered situation of some as compared to others, as is found in an extreme degree in such places as the Undercliff of the Isle of Wight; but geographically, a cause of very considerable importance is the nature of the soil. The air over sandy or sterile ground is heated by direct contact and by radiation, to a degree fartin excess of what happens to air resting on grass-grown or verdant plains; heat proceeding from an obscure source is unable to escape through the air, just as obscure heat-rays may be caught and accumulated in a closed conservatory or in a glass-covered box, so that the air may be raised to a very high temperature: several instances are on record of a temperature of $130^{\circ} \mathrm{F}$. being observed under such circumstances. On the other hand, when the solar heat falls on ground, whether grassy or snow-covered, that will not easily part with it, the air may remain cool, or even cold; as is found in our every-day experience in summer of the pleasantness of a field path as compared with a high road; and as is shown more markedly by the great power of the direct rays of the sun in the Arctic, or at elevated stations in the Alps or Himalayas, whilst the snow is lying all around, and the temperature of the air is far below freezing-point.

But greater far than the effects of differences of soil are the effects of ocean currents, which varm the air to an almost incredible degree. Mr. Croll has calculated that the surfacewater of the North Atlantic, if deprived of the Gulf Stream, would be reduced to a temperature very far below freezingpoint; that the heat which the Gulf Stream disperses into the superincumbent air would, if converted into power, be equal to the united force of some 400 millions of ships such as our largest ironclads. This heat, thrown into the air, is wafted by the south-westerly winds over the north-west of Europe, and wery largely over our own country. It is this that makes the extreme difference between the climate on this side the Atlantic and that on the other, that gives us green fields and open harbours during the winter, whilst in Labrador or Newfoundland they are buried in snow or choked with ice.

The carrying power of water is so great as compared with that of air that the climatic effect of winds heated by contact with hot earth is relatively small. The scirocco of the Mediterranean, a wind heated over the great African desert, has often been referred to as the "snow eater" cf Switzerland. This has been proved to be a mistake. The snow-eating wind of Switzerland is a wind from the Atlantic, warmed by the Gulf Stream, and rendered dry and hot by the condensation of its. vapour as it passes over the mountains. Similar winds have been observed in many different parts of the world-in New Zealand, in Norway, in Greenland, and in North America, where their peculiar dryness, carrying off all moisture, renders the grass so inflammable that the smallest accidental spark lights up a fire which may spread over a country, and is thus the true cause of those immense prairies which are a distinctive feature of North American geography. But such hot winds are quite distinct from such winds as blow from the Sahara, or the Stony Desert of Australia, or from many other sterile tracts of country; winds which are merely the escape of air heated to an extreme degree by contact with the burning soil. These hot winds are for the most part merely disagreeable; but icold winds are very often dangerous; in the North-Western States of America a cold wind, ushering in a violent snow-storm, caused the death of more than 300 people in January, 1873 ; and in many other localities, a cold wind bringing in a sudden fall of temperature through 40 or 50 degrees, is al ways a cause of grave anxiety. Our English "Blackthorn Winter" in April or May is only one, and a subdued instance of the ill-effects of such cold spells.

The presence of moisture in the air, by checking radiation from the ground by night, or during the winter, softens the rigour of the seasons, makes the summers less hot, the winters less cold. It is this that constitutes the difference between "insular" and "continental" climates; it is the want of the vapourscreen which causes "excessive" climates such as we read of 
in the far east, where, as near Khiva, a summer of more than tropical heat is succeeded by a winter of Arctic rigour. In a very extreme degree the climate of Astrakhan contrasts with that of Fuegia, and yet the mean temperature of the two is about the same; but in the one the seasons are excessive, in the other the difference is but small. The difference in the products of the two countries is thus very great : on the one hand, plants requiring great heat, but able to withstand the cold, on the other plants of a more tender nature which can flourish with a very moderate amo:int of warmth ; in the one grapes and corn, in the other fuchsias and veronicas.

In studying climate it is therefore necessary to observe not only the greatest heat and the greatest cold, but also the mean temperature. These can only be observed by means of thermometers, for personal feelings may be the effects of many other causes-of wind or evaporation, or state of health, or peculiarity of constitution, and are absolutely no index to the state of the air temperature.

The lecturer then proceeded to speak of the different kinds of thermometers, severai of which were exhibited, and of the several stands for sheltering them. The Meteorological Society has decided posilively in favour of the Stevenson stand, and directs its observers to record the temperature at 9 A.M. and 9 P.M., as well as the highest and lowest, as registered by the maximum and minimum thermometers. He then described some novel and ingenious contrivances for automatic registering, such as the "turn over" of Messrs. Negretti and Zambra, and the "chronothermometer" of Mr. Stanley, and concluded by pointing out that these instruments were but a means to an end, and that the study of climate was the study of nature in one of her most beautiful and most varied aspects.

\section{Mr. Ley's lecture was on}

\section{Clouds and Weather Signs}

The lecturer dwelt, in the first place, on the unsatisfactory condition of this portion of meteorology, as contrasted with those branches of the science in which instruments are employed. The great impediment to our progress arises from the fact that cloud-observation is, in large measure, an incommunicable art, requiring a special training of the eye. Specimens of the objects of study cannot be exhibited, neither is it-possible, in illustration of the subject, to refer to types of cloud depicted in the well-known paintings of the best artîstś, because the latter, aiming at the production of atmospheric effects, employ the materials most easy to handle, which are commonly the least typical cloud-form:. The old classifica. tion and nomenclature of clouds is highly unsatisfactory, having been framed at a time when the relation of wind and weather to the distribution of barometric pressures was unknown; and with this relation the forms and movements of the clouds are intimately connected.

As regards configuration, clouds seem naturally divisible into two groups, those which atrange themselves in layers, whose vertical diameter is small as compared with its horizontal, and those which assume spherical or hemispherical shapes; and this division is related to certain physical conditions of the atmosplere and of the earth's surface beneath the cloud. It is, however, essential that we should possess some name or system of names to distinguish those clouds which are conveyed by the upper currents, and the term cirrus, with its compounds, must be more closely restricted to this class of clouds than has yet been done. From the use of weather-maps a new science of the winds has originated, on which all attempts at weather forecasting must be based. The movements of the upper clouds afford most valuable information concerning the distribution and movement of the areas of high and low barometric pressure. Rules by which this information may be interpreted, baced in great measure on a former investigation by the lecturer, ${ }^{1}$ are somewhat complex, and cannot well be given in a brief résumé like the present. ${ }^{2}$ It may be sufficient to explain that in the front of an advancing barometric depression there usually extends a bank of the halo-producing cirro-stratus, the exterior edge of which is, roughly speaking, a parabola, the focus of which lies in the line about to be traversed by the centre of the depression. On the right-hand of the centre this bank or sheet is abruptly broken and is succeeded in the rear by local shower-clouds. On the left-hand the sky commonly continues overcast, but the cloud.

" "Relation between the Upper and Under Currents of the Atmosphere *i. iii. p. 437 .

The lectures will shortly be pubitished.
. plane gradually descends until little is to be seen but low stratus. A backing of the upper current takes place until after the centre of the depression has passed. In whatever direction a depression is advancing the same characteristic phenomena are observed. Thus changes in the clouds indicate to us probable alterations of wirid and weather.

While the nimbus, which exists in the front of a depression, first makes its approach evident by changes in the higher cloud-strata, the process of nubification is the converse of this in those local showers which commonly occur on the right-hand and in the rear of a centre of depression, and therefore when the barometer is rising or just about to rise. These latter are developed in an upward direction through the formation of cumulus. The precipitation which occurs in them-always preceded by a change of appearance in the domes of cloud, which assume a soft and cirriform aspect--is attributed to the neutralisation of electricities as the summit of the cloud passes into a higher region; but there are important differences of appearance between those cumuli which are likely, and those which are unlikely, to undergo this transformation,

A physical explanation is given of the ordinary weather signs derived from the colours of the sky, from "visibility," and from unusual refraction. Attention is invited to some peculiar types of cloud, especially to a very elevated turreted stratus, often erroneously termed cirro-cumulus, occurring with high temperature on the south-western borders of anti-cyclones, a forerunner of thunderstorms. The formation of the low-level stratus and of the fog which usually prevails in our winter anti-cyclones, seems to be due to a downward movement of the air at a time when the earth's surface is colder than the atmosphere at a slight elevation above it.

In the course of this lecture sketches of some of the more definite varieties of cloud, with arrows indicating the direction of the currents, and a diagram showing the movements of the upper currents, and the prevailing cloud-types around areas of depression, were exhibited by the aid of the oxy-hydrogen limelight.

\section{THE MOTION OF A LUMINOUS SOURCE AS A TEST OF THE UNDULATORY THEORY OF LIGHT}

I. LTHOUGH the undulatory theory of light may A now be considered as completely established, still any confirming test of a physical theory is in itself interesting as a fresh illustration of a natural truth. Considering how at one time crucial tests of this theory were sought after, it would appear perhaps rather an anomaly that attention should apparently not have been given to the effect attendant on the motion of a luminous source as a test between the two rival (undulatory and corpuscular) theories, and that more especially as the test would appear to be in principle a simple and decisive one. I should have considerable diffidence in directing attention to this point, but no record apparently exists of experiments proposed or attempted with this view. It might be said that the possible existence of practical difficulties in the way of carrying out the test may account for this; but then practical difficulties are seldom allowed to stand in the way, if a theoretic principle be correct; and, unless a thing were seriously proposed and discussed, no attempt would be made to surmount the difficulties that might exist in the way of carrying it out. Sir John Herschel, as far as he touches on this point, would appear to have had the idea that such a test between the two theories could not, in principle, be applicable; for he says ("Outlines of Astronomy," p. 214), speaking of the effect attendant on the motion of a luminous body, "The effect in question, which is independent of any theoretical views regarding the nature of light. . . . \& \&c." It is true he mentions afterwards, in a foot-note, a difference in the effect in the case of the two theories as regards the velocity of light, in the case of a luminous source moving directly towards or from the observer; but the following fundamental difference in the case of the two theories appears not to have been taken into account. 